\title{
Construction Technology and Safety Monitoring Measures of Road and Bridge Engineering
}

\author{
Wei Wang* \\ Transportation Bureau of Gannan Tibetan Autonomous Prefecture, Gannan 747000, Gansu Province, China \\ *Corresponding author: Wei Wang, 870610wangwei@163.com
}

\begin{abstract}
With the acceleration of urbanization and the continuous improvement of urban infrastructure construction, roads and bridges, as an important infrastructure content in China, directly affect people's daily travel. Therefore, the construction and management of roads and bridges must be improved to ensure the quality and safety of roads and bridges and effectively prevent safety accidents. Strengthen the management of road and bridge construction through safety monitoring, improve the safety factor of the project and ensure people's travel safety. This paper mainly analyzes the common diseases and construction technology of road and bridge engineering construction, and puts forward safety monitoring measures.
\end{abstract}

Keywords: Road and bridge works; Construction technology; Safety monitoring measures

Publication date: September 2021; Online publication: September 30, 2021

\section{Introduction}

With the improvement of urbanization construction level, the construction scale and quantity of roads and bridges are expanding, which brings convenience to people's travel. However, due to the complex terrain in China, the construction technology of road and bridge engineering is still immature, and some construction technologies need to be further improved. As a result, there are still many potential safety hazards and quality problems in China's road and bridge engineering, resulting in safety accidents. In recent years, with the wide spread of network information, there are more and more reports of road and bridge accidents, which makes road and bridge safety become the focus of attention. At the same time, the quality and safety of roads and bridges also affects personal and property safety. Therefore, it is necessary to strengthen the research on the key and difficult points and process level of road and bridge construction, so as to ensure the project quality and people's travel safety.

\section{Quality problems in road and bridge construction}

\subsection{Repair of pavement}

In the construction of road and bridge works, a layer of pavement layer needs to be laid on the top layer to protect the road and bridge pavement and prevent vehicles from directly contacting the road and bridge surface, resulting in the wear of the pavement. Moreover, the laying of pavement layer is also conducive to dispersing the pressure on the pavement, reducing road loss and improving service life. In addition, it is also conducive to ensuring the flatness of the pavement and making driving more comfortable ${ }^{[1]}$. However, according to the pavement conditions of roads and bridges, most of the pavement are repaired, and the repair places are increasing. The main reason for this situation is that the quality management in road and bridge construction is not fully implemented, or the pavement protection requirements are not met. On one hand, too much repair will affect the quality of roads and bridges, on the other hand, it will also affect the driving comfort. 


\subsection{Reinforcement corrosion}

Reinforcement is the main construction material in road and bridge engineering construction. The application of reinforcement is conducive to improve the strength of road and bridge buildings, but the material of reinforcement is easy to rust. Once the reinforcement is rusted, the quality and safety of road and bridge will be threatened. There are many reasons for reinforcement corrosion. A series of links need to be experienced from reinforcement procurement to transportation, storage and use, and the duration is relatively long. If the management of any link is not in place, it may cause reinforcement corrosion and affect the quality of roads and bridges.

\subsection{Concrete pouring}

Concrete is the most basic material in road and bridge engineering projects. Concrete contains a lot of cement, and the hydration effect of cement and the cold shrinkage of thermal barrier may cause concrete cracks, which is also an easy quality problem in road and bridge. The causes of concrete cracks are various, including raw material quality problems, unreasonable proportion control, construction quality not meeting the standards, improper operation of construction personnel, etc. Cracks in concrete will inevitably affect the quality and service life of roads and bridges, resulting in huge economic losses and potential safety hazards.

\section{Construction improvement technology of road and Bridge Engineering}

\subsection{Subgrade construction improvement technology}

In road and bridge construction, subgrade construction involves a wide range and many projects, and most of them are field construction. In order to ensure the project quality, it is necessary to do a good job in the management of each construction link in the construction. Firstly, in the excavation of subgrade stonework, various construction methods such as soil loosening method, blasting method or crushing method need to be selected in combination with the soil conditions of the construction site. Secondly, in the base construction of roads and bridges, in order to make the earth rock closely fit the ground, it needs to be treated scientifically in combination with the slope, soil quality and hydrology of the base. During subgrade compaction, to ensure the scientific values of tools and the rationality of soil compaction times, the laying softness and route need to be further optimized. Rolling can be carried out in the way of light first and then heavy. At the same time, during the process of two rolling, the overlapping width of wheel track needs to be half of the wheel width, at least not less than one third ${ }^{[2]}$. The compactness and water content of the soil layer were observed.

\subsection{Pavement Improvement Construction}

In the construction of road and bridge engineering, the pavement structure layer is the key to quality control. The pavement layer can generally be divided into four layers, including the lowest cushion, base layer, base layer and surface layer. Each layer has different functions, and a reasonable construction scheme needs to be adopted in combination with the performance of each layer. Road mixing method and plant mixing method are generally used for the base course of road and bridge construction in China. The road mixing method needs to measure the project first, then prepare the construction materials in combination with the measurement results, then pave and mix, and finally roll into shape for maintenance. The plant mixing method generally requires centralized mixing in the central station. Firstly, the coal ash blocks and soil blocks shall be crushed to ensure that the size of these blocks does not exceed $15 \mathrm{~mm}$. At the same time, the batching shall be strictly controlled and the mixing amount and water content shall be well controlled before mixing. For some engineering projects with high quality level, plant mixing is generally adopted and paved by paver, which is conducive to ensuring construction quality and efficiency. Most of the road 
and bridge pavements in China are paved with cement concrete or asphalt. Cement concrete pavement is a kind of rigid pavement, which needs to be transported by installing side touch and dowel bar, and then vibrate, pave, absorb water, repair and maintain the concrete. The paving of asphalt pavement is complex, and it needs to be paved in layers. The mineral aggregate is paved at the bottom layer, and the upper layer is paved after rolling. In order to ensure the stability of the pavement during the paving process, it is necessary to ensure that the pavement is paved in a relatively dry climate in spring and summer. After paving, the traffic can be opened and the pavement can be compacted. Asphalt is generally mixed in plant, mixing asphalt and mineral aggregate, and then transported to the construction site.

\subsection{Common disease prevention technology}

Some diseases often occur in road and bridge construction. Prevention in advance is conducive to reduce the harm of diseases and ensure the safety of pavement. Through investigation and research, it is found that there are many problems in China's road engineering construction, such as pavement falling off, reinforcement corrosion and concrete cracks. For different problems, we need to do a good job in protection. In the selection of asphalt concrete, we need to select materials with strong stability and waterproof, and accurately calculate the pavement thickness of concrete to realize the protection of bridge deck pavement

[3]. Combined with the problem of reinforcement corrosion, do a good job in the management of each link, and properly use rust remover to protect the reinforcement. Concrete cracking can be prevented by strict control of raw materials and optimization technology of proportioning, mixing and paving.

\section{Safety monitoring strategy for road and bridge construction}

\subsection{Build a scientific safety monitoring system}

In order to ensure the construction safety of road and bridge works, the construction unit needs to build a special safety management system in combination with the construction requirements, and refine the construction safety management system according to the construction requirements. At the same time, the state and government departments need to pay more attention to safety management and provide corresponding guiding policies to promote the rapid development of road and Bridge undertakings. According to relevant laws and regulations and in combination with project construction requirements, scientifically plan rules and regulations, do a good job in the management of each department, clearly divide the responsibilities of each department, and implement the responsibilities to each department and management personnel. In addition, build a scientific management system and clarify the construction quality requirements. During the design period of project construction, it is necessary to reasonably calculate the construction cost according to the project construction conditions and requirements, and ensure that the budget of each link is sufficient. Finally, ensure the ability and literacy of management personnel to complete the construction requirements and specifications.

\subsection{Improve project management quality}

In the construction of road and bridge engineering, it is necessary to strengthen the safety monitoring of the construction site, including the material quality, construction technology and construction procedures at the construction site, and timely find the quality and safety problems through real-time dynamic supervision. At present, the third-party supervision company is generally responsible for the supervision of construction projects in China. In order to ensure the supervision efficiency, the supervision unit needs to make the supervision plan before the construction of the project, and ensure the feasibility of the implementation of the plan. The supervision work needs to include detection technology, key project contents, etc., which need to be continuously optimized and improved in combination with the construction project requirements, and the supervision records shall be made. 


\section{Conclusion}

To sum up, there are many common diseases and problems in the construction of road and bridge works, which will have a certain impact on the quality and safety of road and Bridge bodies and threaten the safety of pedestrians' lives and property. Therefore, it is necessary to strengthen the quality and safety management of road and bridge engineering, optimize construction technology, and prevent common diseases in advance. Additionally, do a good job in quality supervision during construction. The third-party supervision company needs to connect with the construction unit on the construction quality requirements, do a good job in construction quality control in strict accordance with the corresponding laws, regulations and management specifications, find problems in time, and make rectification in time, so as to ensure the scientific value and preciseness of road and bridge construction raw materials, construction procedures and construction technology, Thoroughly implement the construction safety supervision and improve the quality and safety management level of road and bridge construction.

\section{Disclosure statement}

The author declares no conflict of interest.

\section{References}

[1] Sun G, 2021, Research on Construction Technology and Safety Monitoring of Road and Bridge Engineering. Digital design (Part 2), 10(3): 111-112.

[2] 2020, Discussion on Construction Technology and Safety Monitoring of Road, Bridge and Tunnel Engineering. Commodity and Quality, (7): 195.

[3] Wang H, 2019, Discussion on Construction Technology and Safety Monitoring of Road, Bridge and Tunnel Engineering. Commodity and Quality, (9): 267. 